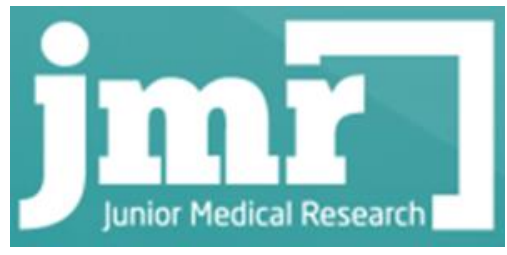

Full Text Article Open Access

Images in clinical practice

\title{
Spinal Osteoid Osteoma and scoliosis: who is the painful?
}

Jlalia Zied ${ }^{1,3^{*}}$, Kaffel Dhia ${ }^{2,3}$.

1: pediatric Orthopedics department, Kassab Institute of orthopedic surgery, Tunis, Tunisia

2: Rheumatology department, Kassab Institute of orthopedic surgery, Tunis, Tunisia

3: College of medicine Tunis, Tunisia

*Corresponding author

Correspondence to:

jlalia.zied@gmail.com

Publication data:

Submitted: January 2,2019

Accepted: January 25,2019

Available Online: April 7,2019

This article was subject to full peerreview.

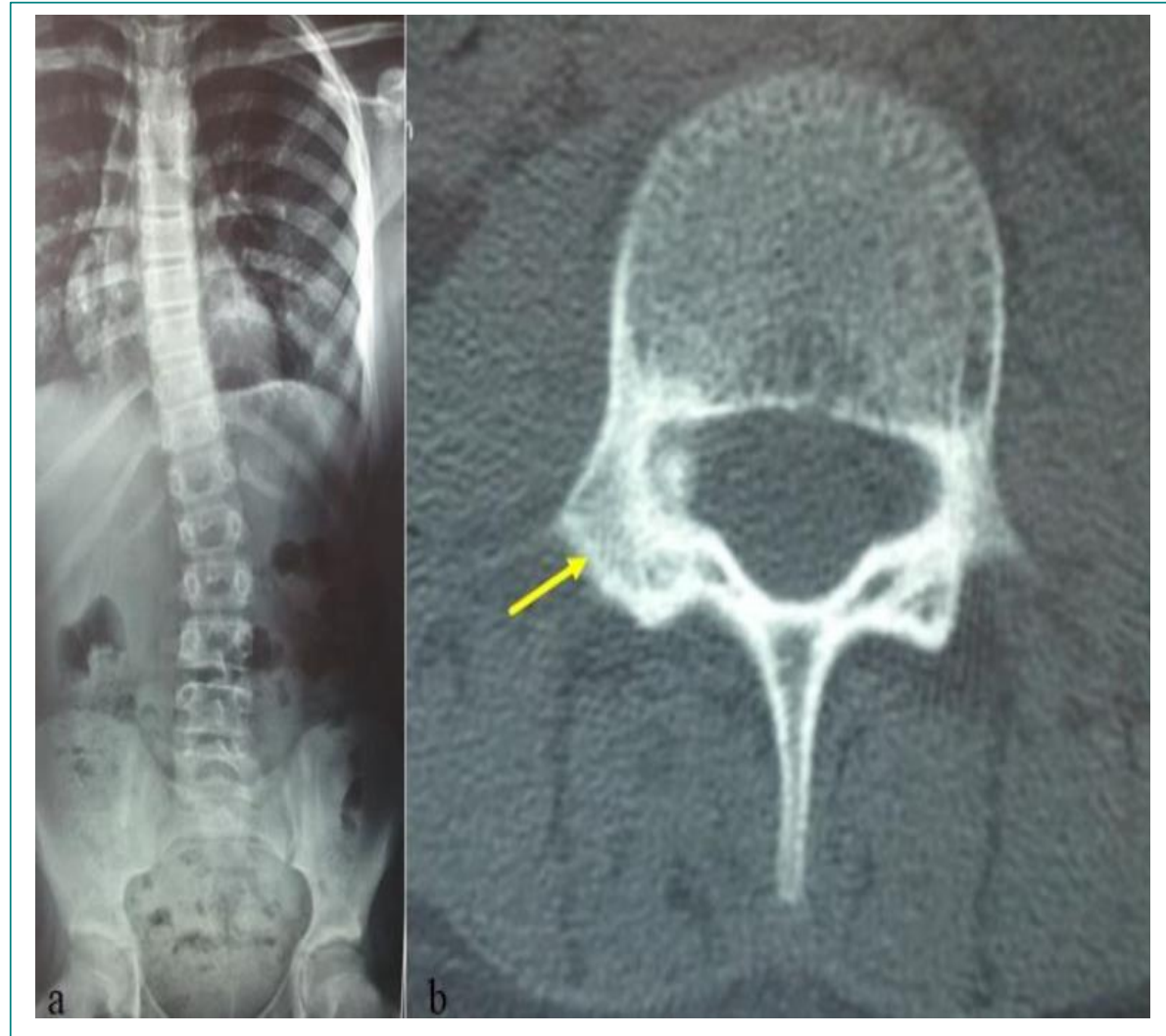

Case presentation:

Ten-year-old girl was referred to our clinic for back pain and stiffness of the spine. X-ray of the spine showed a dorsal scoliosis with no other abnormality (figure 1a). Computed Tomography (CT) showed the nidus in right pedicle of the 3rd lumbar vertebra (figure $1 \mathrm{~b}$ ). The diagnosis of Osteoid osteoma was retained and confirmed after surgical resection and pathological examination. Osteoid osteoma (O.O) accounts for $10 \%$ to 20 $\%$ of benign bone tumors [1]. Up to $25 \%$ of all 0.0 are found in the spine. Two thirds of spinal 0.0 manifest as painful scoliosis [2]. The diagnosis of the tumor is usually delayed because easily missed on standard X-ray investigation. Systematic CT or MRI with dynamic contrast would be recommended for young patients presenting with painful scoliosis [3].

Citation: Jlalia Z, Kaffel D. Spinal Osteoid Osteoma and scoliosis: who is the painful? Junior Medical Research. 2019; 2(1):18-19.

Jlalia et al (c) All rights are reserved. Submit your manuscript: www.jmedicalresearch.com 


\section{Conflict of interest: none}

\section{References:}

[1] J Zhang H, Niu X, Wang B, He S, Hao D. Scoliosis secondary to lumbar osteoid osteoma: A case report of delayed diagnosis and literature review. Medicine (Baltimore). 2016 ;95: e5362.

[2] Balioglu MB, Albayrak A, Atici Y, Sokucu S, Tacal MT, Kaygusuz MA. The effect of simple local resection on pain and scoliotic curve in patients with scoliosis secondary to osteoid osteoma and osteoblastoma in the spine. Acta Orthop Traumatol Turc. 2016; 50:330-38.

[3] Mahmoudi A, Khattala K, Rami M, Elmadi A, Lamiae C, Youssef B, et al. Scoliosis revealing an osteoid osteoma. Pan Afr Med J. 2013; 14:58. 